\title{
Unilateral lattice dystrophy of the cornea
}

\author{
R. F. MEHTA \\ From the Department of Ophthalmology, University of Sheffield
}

SUMMARY Five cases of unilateral and 1 case of bilateral lattice dystrophy of the cornea in 1 family are reported. The diagnosis was made on the basis of the characteristic clinical appearance. The unilateral lesions were generally asymptomatic and required no treatment.

Lattice dystrophy of the cornea was first described by Biber (1890) and again by Haab (1899) and Dimmer (1899). It usually becomes evident towards the end of the first decade of life, though the characteristic changes have been observed earlier, at 2 years (Stansbury, 1948), or later, in the third or fourth decades (Ramsay, 1957). Usually at about the 20th year the lesions become macroscopically obvious and classically occur bilaterally.

The dystrophy is characterised by the presence of opacification in a linear pattern in the superficial stroma, usually in the central region of the cornea. The corneal epithelium is spared, and therefore vision is good until the third or fourth decade. Corneal sensitivity is decreased when more severe changes occur. The stroma around these pathological changes remains clear until later in life. The opacities may eventually become confluent, forming a greyish white, central corneal leucoma. The clinical picture of corneal lattice dystrophy includes recurrent erosions, early decrease in vision due to irregular astigmatism, and later marked decrease in vision as the stromal lesions become denser. Lattice dystrophy of the cornea is hereditary and transmitted in an autosomal dominant manner.

Unilateral lattice dystrophy is a rare disease and no family with it has been reported. The first cases of unilateral lattice dystrophy were reported by Netchaiewa (1937) and subsequently by Hugonnier (1947). Ramsay (1957) reported 10 cases of lattice dystrophy, 1 of which was unilateral. Reshmi and English (1971) reported 1 case of unilateral lattice dystrophy in a 60-year-old woman. The most recent report of unilateral lattice dystrophy is of 6 isolated cases by Rabb et al. (1974).

This paper describes 5 cases of unilateral and 1 case of bilateral lattice dystrophy in 1 family. These unilateral cases have certain features which distin-

Correspondence to R. F. Mehta, FRCS, Department of Ophthalmology, Hallamshire Hospital Medical School, Glossop Road, Sheffield S10 2JF. guish this entity from the classic form of bilateral lattice dystrophy.

Case histories

CASE 1

Subject II-2, Fig. 1. A 56-year-old white man was seen by a consultant ophthalmologist because his optician noticed a left corneal lesion and he could not improve his left visual acuity to more than $6 / 12$ with corrective lenses. He was seen in the Eye Clinic, University of Sheffield, for second opinion. Examination revealed a unilateral lattice dystrophy involving the left cornea. Four years previously he had attended the Ophthalmic Casualty Department in Sheffield and was treated with antibiotic drops for left keratitis.

The lesion involving the left eye consisted of fine linear opacities, radiating from the central cornea (Figs. 2 and 3). The central cornea showed 1 nebular opacification. The limbal region remained clear.

The right eye had been asymptomatic and was normal on examination, with corrected visual acuity of $6 / 6, \mathrm{~N} 5$. There was no staining of the cornea with fluorescein or rose Bengal, and corneal sensation was normal.

His father suffered from bilateral corneal dystrophy and had been admitted twice in 1978 to Barnsley General Hospital for hypopyon ulcer of the right eye. His aunt lost the sight of her right eye owing to painless perforation of cornea, had the eye enucleated, and wears a prosthesis. His father's aunt had one eye enucleated, but the detailed history is not known. His mother died 26 years ago, and there was no history of eye trouble.

CASE 2

Subject I-1, Fig. 1. This 79-year-old white man, the father of case 1, was seen at Barnsley General Hospital with a history of gradually diminishing vision of both eyes and repeated attacks of sore eyes since the age of 50 years. Examination revealed 


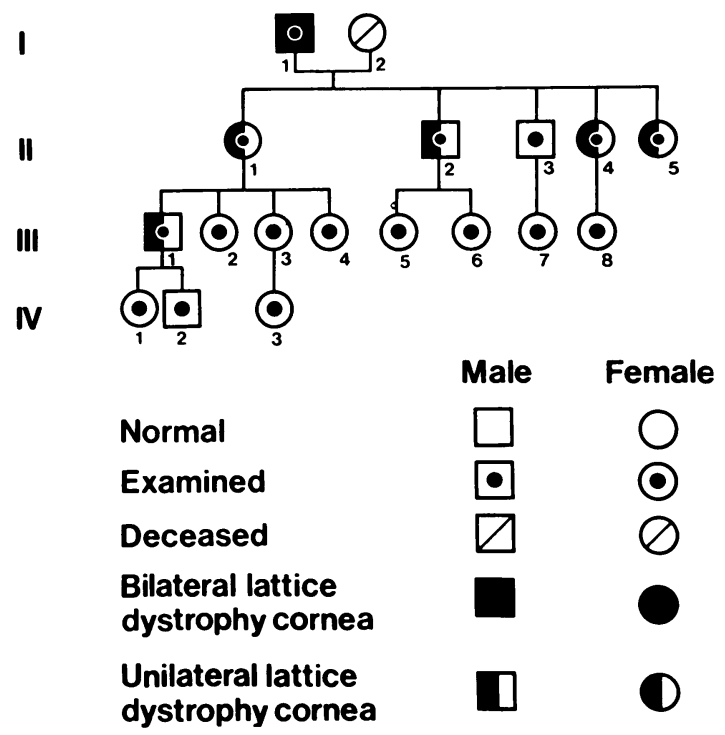

Fig. 1 Pedigree of a family

bilateral lattice dystrophy of the cornea, a right corneal ulcer with hypopyon, and some diminished sensation of the right cornea. The lesion involving the left cornea consisted of fine, linear opacities, radiating from the central cornea; numerous areas just adjacent to the central cornea showed nebular opacification. The limbal region remained clear. The corrected vision of the right eye was perception of light and of the left eye was 6/60. There were some cortical lens opacities involving the right eye more than the left.

The following patients were seen as part of the family study.

CASE 3

Subject II-1, Fig. 1. A 60-year-old white married woman gave a history of slightly blurred vision in the left eye recently; otherwise she was asymptomatic. The corrected vision in the right eye was $6 / 6$, and the left eye was $6 / 9$ part. Examination revealed lattice dystrophy of the left cornea. The right cornea was normal. There was no history of epithelial erosion or reduced corneal sensitivity, and the corneal sensation was normal in each eye.

CASE 4

Subject II-4, Fig. 1. A 49-year-old married white woman gave a history of measles at the age of 4 years followed by a sore left eye and left convergent squint, the vision being very poor since then. Examination revealed a moderate left convergent squint with glasses for near and distance, corrected vision right eye $6 / 6$, left eye $6 / 60+1$. The right

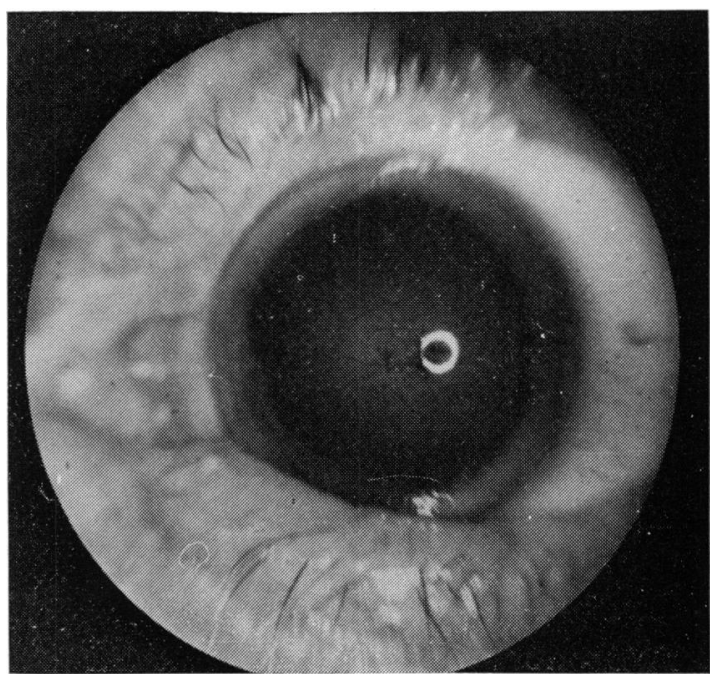

Fig. 2 Lattice dystrophy of the cornea, left eye (photograph by fundus camera)

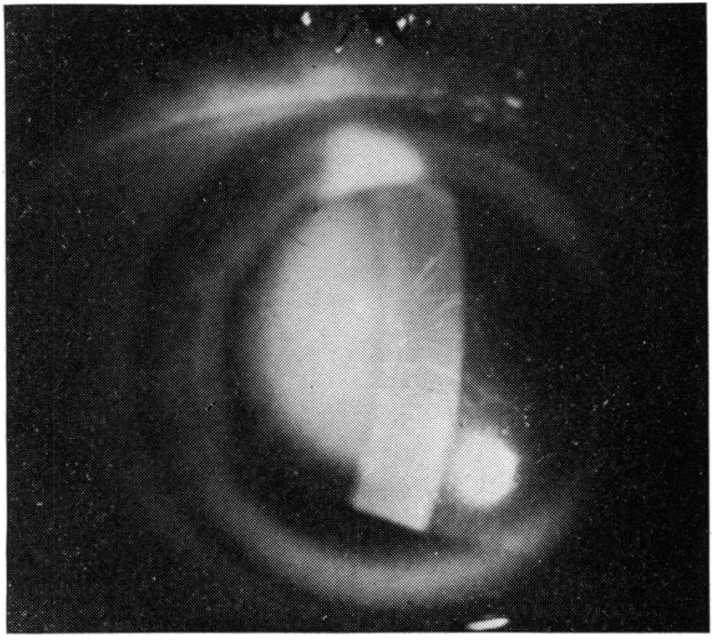

Fig. 3 Lattice dystrophy of the cornea, left eye (photograph by slit-lamp microscope camera)

cornea was normal with normal sensation and no staining. Left corneal examination revealed lattice dystrophy of the superficial stroma with central corneal scarring. The corneal sensation was normal, and there was no staining of the cornea.

\section{CASE 5}

Subject II-5, Fig. 1. A 43-year-old unmarried white woman gave a history of slightly blurred vision in her right eye. Her vision was right eye $6 / 9$, left eye 6/6, not improved by glasses. Examination revealed corneal lattice dystrophy in the superficial stroma of the right eye with linear branching 
opacities in the central stroma. There was no epithelial staining, and the corneal sensation was normal. The left cornea was normal.

\section{CASE 6}

Subject III-1, Fig. 1. A 38-year-old married white man gave a history of inability to see small print with his right eye; otherwise he was asymptomatic. His vision was right eye $6 / 6-2$ and N5 with difficulty, left eye $6 / 5$ and $N 5$, not improved by glasses. Examination revealed lattice dystrophy of the right cornea.

The left cornea was normal. The corneal sensation was normal bilaterally and there was no staining of the cornea.

Subject II-3 (Fig. 1), subjects III-2, 3, 4, 5, 6, 7 , and 8 , and subjects IV-1, 2, 3 were also seen. Examination revealed no lattice dystrophy of the cornea and all had normal vision in both eyes. Corneal sensation was normal bilaterally and there was no corneal staining.

\section{Discussion}

The aetiology of lattice dystrophy is unknown and the pathology has been a matter for disagreement. There are basically 2 theories. The first is that lattice dystrophy constitutes a primary degeneration of stromal collagen fibres (Fuchs, 1925; Dark and Thomson, 1960). The second theory is that corneal nerves are primarily affected, with degeneration of the collagen fibres as the consequence of nutritional disturbance due to pathologic innervation (Pillat, 1922, 1923, Vrabec, 1957; Wolter and Henderson, 1963). Since 1967 many authors, including Klintworth (1967), Smith and Zimmerman (1968), and Meretoja (1972), have shown that deposition of amyloid is involved in lattice dystrophy of the cornea. The disease may therefore reflect a metabolic disturbance.

The 5 cases of unilateral lattice dystrophy reported here were either asymptomatic or had minimal symptoms, and all patients except one had $6 / 12$ or better visual acuity in the affected eye. In 1 case the visual acuity was $6 / 60+1$ in the affected eye, but there was a convergent squint in the affected eye and therefore the diminished vision in that eye may be due to partial amblyopia. The late onset, with minimal symptoms and preservation of relatively good vision in the affected eye, distinguishes it from the classic form of lattice dystrophy, but in family L described by Dark and Thomson (1960), visual disturbance and ocular discomfort began in the fourth decade or later. No pathological specimens of these unilateral lesions have been obtained.

Since unilateral lattice dystrophy is associated with minimal symptoms, patients do not seek medical assistance, and many cases probably go undetected.

The family study is consistent with autosomal dominant transmission. The ages of the unaffected members range from 5 years to 36 years, and some of these may yet develop the condition.

I thank Mr N. L. McNeil, consultant ophthalmologist, who kindly allowed me to report his cases, and Mr A. Stanworth for his guidance.

\section{References}

Biber, H. (1890). Über einige seltenere hornhauterkrankungen: die oberflächliche gittrige keratitis. Inaugural Dissertation, pp . 35-42. A. Diggelmann: Zurich.

Dark, A. J., and Thomson, D. S. (1960). Lattice dystrophy of the cornea: a clinical and microscopic study. British Journal of Ophthalmology, 44, 257-279.

Dimmer, F. (1899). Uber oberflächliche gitterige hornhauttrübung. Zeitschrift für Augenheilkunde, 2, 354-361.

Duke-Elder, S., and Leigh, A. G. (1965). System of Ophthalmology, Vol. VIII, Diseases of the outer eye, part 2, pp. 933-939. Mosby: St. Louis.

Fuchs, A. (1925). Zur kenntnis der gitterigen hornhautentartung; Haab-Dimmer. Zeitschrift für Augenheilkunde, 57, 159-186.

Haab, O. (1899). Die gittrige keratitis. Zeitschrift für Augenheilkunde, 2, 235-237.

Hugonnier, R. (1947). Dégénérescence grillagée de la cornée, de l'apparition relativement tardive. Annaels d'Oculistique, 180, 483-487.

Klintworth, G. K. (1967). Lattice corneal dystrophy: an inherited variety of amyloidosis restricted to the cornea. American Journal of Pathology, 50, 371-383.

Meretoja, J. (1972) Comparative histopathological and clinical findings in eyes with lattice corneal dystrophy of two different types. Ophthalmologica, 165, 15-37.

Netchaiewa, E. A. (1937). Gittervornice hornhautrubung an eine hauge (unilateral lattice dystrophy of the cornea). Vestnik Oftalmologii, 11, 639-640.

Pillat, A. (1922). Über die gittrige und andere formen degenerativer hornhauterkrankungen. Klinische Monatsblätter für Augenheilkunde, 69, 681-682.

Pillat, A. (1923). Über die gittrige und andere formen degenerativer hornhauterkrankungen. Zeitschrift für Augenheilkunde, 49, 313-326.

Rabb, M. F., Bloodi, F., and Boniuk, M. (1974). Unilateral lattice dystrophy of the cornea. Transactions of the American Academy of Ophthalmology and Otolaryngology, 78, 441-444.

Ramsay, R. M. (1957). Familial corneal dystrophy; lattice type. Transactions of the American Ophthalmological Society, 55, 701-739.

Reshmi, C. S., and English, F. P. (1971). Unilateral lattice dystrophy of the cornea, report of a case. Medical Journal of Australia, 1, 966-967.

Smith, M. E., and Zimmerman, L. E. (1968). Amyloid in corneal dystrophies. Archives of Ophthalmology, 79, 407-412.

Stansbury, F. C. (1948). Lattice type of hereditary corneal degeneration. Archives of Ophthalmology, 40, 189-217.

Vrabec, F. (1957). Etude neurohistologique d'un cas de dystrophie grillagée de la cornée. Ophthalmologica, 133, 160-169.

Wolter, J. R., and Henderson, J. W. (1963). Neurohistology of lattice dystrophy of the cornea. American Journal of Ophthalmology ,55, 475-484. 